VISÃO HISTÓRICA DA ARTE ,BREVES ENFOQUES

ERISMILTA SUCUPIRA FERRO CARNEIRO*

*Doutora em Ciências da Educação pela FICS- Faculdad interamericana de ciências sociales del Asuncion Paraguai.

RESUMO

A história da Arte, como área do conhecimento, segundo Pareyson (1983 apud FUSARI; FERRAZ, 2001, p. 116), tem por função determinar "o nexo da arte com outras manifestações de uma mesma civilização e, por outro lado, [...] determinar [...] o lugar de uma obra, ou de um artista no interior de uma tradição artística". Assim, para compreender a trajetória histórica da Arte, é preciso refletir os problemas, a solução artística e a estética nela envolvidos.

Estudar a arte historicamente, não significa estudar simplesmente fatos históricos no tempo e no espaço, bem como o estilo desta; mas significa caracterizá-la pelas teorizações e práticas de estudos, análises históricas e críticas com relação a objetos e criações artísticas produzidas pelo homem, ao longo de sua existência, em lugares diferentes.

O texto acima remete estudar a história da arte, levando em consideração os elementos existentes entre a arte e a sociedade, indígena ou não. As implicações de produção, recepção e distribuição artísticas e, ainda, o modo de analisá-las no tempo e no espaço, devem ser contextualizadas para detectar como a arte interfere na sociedade no tempo em que por ela é condicionada.

\title{
PALAVRA CHAVE
}

História, Arte , Indígena , tradição , cultura , Dança , Educação , Escola 
RESUMEN

La historia del arte, como área de conocimiento, según Pareyson (1983 apud FUSARI; FERRAZ, 2001, p. 116), tiene la función de determinar "el nexo del arte con otras manifestaciones de la misma civilización y, por otro lado, [. ..] determinar [...] el lugar de una obra o artista dentro de una tradición artística ". Por lo tanto, para comprender la trayectoria histórica del arte, es necesario reflejar los problemas, la solución artística y la estética involucrada en él.

Estudiar arte históricamente no significa simplemente estudiar hechos históricos en el tiempo y el espacio, así como su estilo; pero significa caracterizarlo mediante la teoría y la práctica de estudios, análisis históricos y críticos de objetos y creaciones artísticas creadas por el hombre a lo largo de su existencia en diferentes lugares.

El texto anterior se refiere al estudio de la historia del arte, teniendo en cuenta los elementos existentes entre el arte y la sociedad, indígenas o no. Las implicaciones de la producción artística, la recepción y la distribución, así como la forma de analizarlas en el tiempo y el espacio, deben contextualizarse para detectar cómo el arte interfiere con la sociedad en el momento en que está condicionada por ella.

\section{PALABRA CLAVE}

Historia, Arte, Indígena, Tradición, Cultura, Danza, Educación, Escuela

Partindo do pressuposto de que a arte é objeto de estudo de várias ciências, dentre elas, a antropologia, a psicologia, a sociologia, além da filosofia, da historia, da religião etc., a mesma só pode ser compreendida a partir de uma abordagem, que comungue as diversas formas de entendê-la. Assim, a melhor abordagem é aquela que permite e admite a conjunção das diversas perspectivas, haja vista a capacidade da arte em mudar histórica e culturalmente e ainda cumprir papéis diversos, conforme o contexto no qual é produzida, ou melhor, ela pode servir para fins diversificados de cunho prático, ritualístico, estético, educativo etc., bem como 
determinar momentos histórico-culturais de um povo ou grupo étnico de uma determinada sociedade.

Nesse contexto, a arte é apresentada, como produção artística, do ponto de vista histórico e antropológico, onde essa mesma arte marca períodos históricos, situando-os no tempo e no espaço, partindo das pinturas rupestres dos aborígines produzidas em rochas, até a pintura de um quadro cubista, no qual são utilizados diversos tipos de tintas sintéticas. Essas produções artísticas, consideradas efetivamente obra de arte, foram produzidas pelo homem em determinado período histórico, com um valor cultural inestimável.

Para entender e/ou compreender a história de um povo, necessário se faz observar as produções artísticas destes, vez que os períodos históricos podem suscitar ou mesmo inibir as produções artísticas, isto quando o regime de repressão entra em ação, castrando e podando as manifestações culturais, se essas denotam servirem como instrumentos de insubordinação ou veiculo de divulgação ideológica contra o domínio imposto. Certo período na história do Brasil - durante o regime militar, várias obras de arte foram censuradas por representar perigo ao regime, levando muitos artistas ao exílio.

A arte, enquanto produção artística pode ser vista o quão importante é para determinar épocas e marcar variantes culturais. Povos com culturas diferentes tendem produzir objetos de arte com formas, função e significação simbólicas, também distintas entre si sem, no entanto, perder a beleza e a criatividade das peças, o que favorece a comercialização, haja vista o papel desempenhado pela obra de arte na sociedade capitalista industrial (com o apogeu da indústria do turismo) está sendo apresentado com significado puramente estético e econômico.

É possível ver que a arte, ao se materializar artisticamente, quando na pintura, literatura, música, escultura, arquitetura, na cerâmica, determina a identidade de seu feitor, através dos traços empregados conscientemente, para adequar sua obra ao tempo.

A arte adquire sentido para o ser humano, na medida em que ele organiza o mundo e que, através das percepções e interpretações, os organismos externos da realidade são mapeados nos sistemas internos do ser, e o cérebro humano vai também se desenvolvendo no contato com essa realidade. Na visão de Buoro (2000, p. 20) "a arte, portanto se faz presente, desde as primeiras manifestações de que se tem conhecimento, como linguagem, produto da relação homem/mundo".

Nesse sentido, cabe questionar: qual a importância da arte na vida do homem? Sendo que as especificidades psicológicas, sociais e culturais estão presentes na vida do homem, relacionando-o com a natureza e com o mundo que o cerca, construindo as possibilidades da sua sobrevivência e do seu desenvolvimento. 
Olhando a arte, como linguagem expressiva de interpretação e representação, vê-se que propicia ao homem contato com ele mesmo e com o mundo, dessa forma ele passa a entender tudo ao seu redor e relacionar-se com ele, haja vista que o conhecimento do meio é vital para sua sobrevivência, onde as habilidades de identificar, selecionar, classificar, analisar, sintetizar e generalizar faz parte da organização do ser humano, bem como para desenvolver atividades práticas.

Em cada momento específico e em cada cultura, pode-se dizer que o homem tenta satisfazer suas necessidades socioculturais, utilizando-se de sua vontade e necessidade da arte que, por sua vez, imbuída de conhecimentos, vem, ao longo do tempo, aprimorando-se, evoluindo. Kandinsky (1990 apud BUORO, 2000, p. 24) assinala que "cada época de uma civilização cria uma arte que lhe é própria e que jamais se verá renascer".

Essas mudanças, que a arte sofre, são produtos das transformações processadas na realidade social que, conseqüentemente, reflete nos meios da produção artística, evidenciando, sempre, o momento histórico do homem. Cada época, com suas características peculiares, contando o seu momento de vida, fazem uma trajetória própria na representação e manifestação cultural, como questão de sobrevivência - a arte.

Encontrar um conceito para Arte é, antes de tudo, conceber a si mesmo um legado de satisfação, isto porque tanto o que realiza como o que a estuda sempre vê nela uma concepção própria, mesmo inconscientemente; segundo Pareyson (1983 apud BUORO, 2000, p. 25) "a arte encontrada na História do pensamento ocidental agrupa três vertentes principais que predominam alternadamente em diferentes momentos históricos: Arte como fazer, como conhecer e como exprimir" uma visão teórica embasada na estética da formatividade, ou melhor, no formar da atividade artística, isto é, um executar, produzir e realizar arte nos vários mundos sociais: local, nacional e internacionalmente.

Freitas (1994, p. 76) pontua que "para Vygotsky a arte se apresenta como produto da atividade humana, onde o conteúdo não é introduzido de fora da obra, mas sim criam nela sentimentos", sentimentos esses capazes de entender a função da arte na vida da sociedade e na vida do homem como ser sócio-histórico-cultural. Portanto, entender a arte como resultado do embate homem/mundo, ela é vida, o que vale dizer que o homem interpreta sua própria natureza, construindo formas, ao mesmo tempo em que descobre, inventa figura e conhece, adequandoa a seu tempo e a seu mundo interior.

Considerando que a arte é uma linguagem manifestada desde os primeiros momentos da história humana e estruturada, de acordo com a época e a cultura, onde o conhecimento contribui para o entendimento do homem e do mundo. Portanto o que se espera da arte na educação é que ela possa propiciar uma relação mais consciente no indivíduo do mundo para o 
mundo, contribuindo na formação de pessoas mais críticas e criativas, para atuarem na transformação da sociedade.

Na visão de Decroly (1996) a criança externa sua aprendizagem, através de qualquer meio de linguagem, integrando os conhecimentos adquiridos, de maneira globalizadora. Demonstrando através de linguagens múltiplas, que tanto as palavras quanto o corpo, o desenho, a construção e a arte, corrobora para o aluno externar e compartilhar o que aprendeu.

A importância da Arte no processo educativo é indiscutível, vez que está imbuída de características ímpares, contribuindo para o desenvolvimento individual do aluno, tornando-o capaz de aprender a organizar suas experiências por meio do sentimento estético, utilizando a educação como instrumento fortalecedor desses sentimentos.

Como visto anteriormente, a arte esteve sempre presente na vida do homem, porém, como objeto da educação, é bem recente. O processo de incluir a Arte no contexto escolar, como disciplina, denominada Educação Artística, só aconteceu a partir da década de 70, com o advento da Lei de Diretrizes e Bases 5.692/71. Aqui houve uma melhoria do ensino da Arte na educação escolar, quando da incorporação de atividades artísticas voltada ao processo expressivo e criativo dos alunos. Nessa visão, passou a compor um currículo que sugeria a valorização da tecnicidade e profissionalização.

Assim, a Educação Artística, apresentava em sua concepção, tecnicista, especial preocupação com a expressividade individual, no que demonstrava insuficiência quanto ao aprofundamento do conhecimento da Arte em si, da sua história e linguagem artísticas, enquanto que a Arteeducação caracteriza seu posicionamento idealista, voltado para a subjetividade com o mundo, contendo em seu bojo novas metodologias de ensino e aprendizagem, re-valoriza o professor da área, discutindo e propondo um redimensionamento do trabalho escolar.

Segundo Fusari e Ferraz (2001, p. 15) “a educação através da Arte é na verdade, um movimento educativo e cultural que busca a constituição de um ser humano completo, total, dentro dos moldes do pensamento idealista e democrático", onde o ser humano é valorizado em seus aspectos intelectuais, morais e estéticos, procurando despertar sua consciência individual, harmonizada ao grupo social ao qual pertence.

Segundo Varela (1988, p. 2):

O espaço da arte-educação é essencial à educação numa dimensão muito mais ampla, [...] é território que pede presença de muitos [...] desempenha papel integrador plural e interdisciplinar no processo formal e não-formal da educação (VALERA, 1988, p. 2).

Assim, sabe-se que esse movimento busca a autoafirmação do ensino da Arte, enquadrando-a como disciplina ao currículo, uma vez que se acredita que os elementos mobilizadores da arte devem manter-se presentes, como um saber a ser apreendido gradativamente pelos 
estudantes, ao longo do processo escolar, cabendo ao professor organizar um trabalho consistente, contendo atividades artísticas, estéticas, programa de teoria e história da Arte, inter-relacionados com a sociedade, dando ênfase à cultura, de forma que os alunos conheçam e vivenciem aspectos técnicos, inventivos, representativos e expressivos na música, no desenho, no teatro e na dança.

Contudo, acredita-se ser possível atingir um conhecimento mais amplo e aprofundado da arte, bastando para isso incluir ações de ver, ouvir, mover-se, sentir, pensar, descobrir, exprimir e fazer, a partir de elementos da natureza e da cultura, analisando-os, refletindo, formando, transformando-os. É nessa abrangência que o ensino da Arte deve ser concebido pela comunidade escolar.

\subsection{A Educação Escolar Indígena no Brasil}

A educação para os índios, quando do processo ensino-aprendizagem na América Latina, de forma geral, apoia-se nos modelos europeus e remonta ao período da chegada dos descobridores e colonizadores, época em que as missões religiosas iniciaram o processo de civilização, preparando os indígenas para a formação do homem perfeito, conhecido como o bom cristão.

No Brasil, a educação para os povos indígenas como no resto da América Latina seguia o modelo tradicional tendo como base os princípios da conversão religiosa e o uso de mão de obra, que se caracterizavam pela transmissão de informações consideradas verdades absoluta, onde o aluno era um mero receptor e reprodutor de conteúdos. Este modelo contribuiu para a destruição da cultura indígena e da forma de organização existente.

Segundo Silva (2001, p. 96)

Quando a escola foi implantada em área indígena, as línguas, a tradição oral, o saber e a arte dos povos indígenas foram discriminados e excluídos da sala de aula. A função da escola era fazer com que os índios desaprendessem as suas culturas e deixassem de ser índios (SILVA, 2001, p. 96).

Ao falar sobre a história da educação escolar entre os povos indígenas no Brasil, Ferreira (2001) a divide em quatro fases. A primeira inicia-se na época do Brasil Colônia, quando a escolarização dos índios esteve a cargo dos missionários católicos da Companhia dos Jesuítas, que até a sua expulsão em 1795 usaram a educação escolar, entre outras coisas para impor o ensino obrigatório em Português como forma de promover a assimilação dos índios á civilização cristã (MILHOMEM, 2008, p. 96). 
Em Roraima, esse trabalho foi desenvolvido, primeiramente por grupos de missionários e, posteriormente, pelos padres Beneditinos, no final do século XIX. Pelo visto, o modelo de educação imposta sempre respondeu aos interesses dominantes de quem "capacitava" os índios, para servi-los nos mais diversos labores, pagando por sua mão-de-obra salário não condizente com o serviço prestado, ora na construção civil, ora como empregadas domésticas, tanto em casa de família, como nas fazendas, etc.

A segunda fase da educação escolar indígena é marcada pela criação do Serviço de Proteção ao Índio (SPI), em 1910. A terceira fase inicia-se no final dos anos 60 e vai até o final dos anos 70 , ainda durante o período militar, quando surgem organizações não governamentais (ONGs) voltadas para a defesa dos índios. Destacam-se entre elas o Conselho Indigenista Missionário (CIMI), a Operação Amazônia Nativa (OPAN), a Comissão Pró-Índio (CPI), o Centro de Trabalho Indigenista (CTI), o Centro Ecumênico de Documentação e Informação (CEDI), e a Associação Nacional de Apoio ao Índio (ANAI).

A partir dos anos 80, inicia-se a quarta fase da História da Educação Indígena quando o movimento indígena começa a se organizar passando a exigir uma política de escolarização do estado que leve em consideração e respeite as diferenças e as especificidades de cada povo.

A luta por uma educação escolar específica, diferenciada e de qualidade, diz respeito a todos os povos indígenas do Brasil, porém, só a partir dos anos 80 , os primeiros projetos alternativos de Educação Escolar Indígena, demonstram a necessidade de mudanças e, assim, as práticas educativas contemplam a realidade das comunidades indígenas, resgatando a língua materna e valorizando a cultura.

Avanços significativos, no que diz respeito às políticas educacionais voltadas para a questão indígena começam a manifestar-se, mas só com o advento da Constituição Federal de 1988, é que a Educação Escolar Indígena teve seu reconhecimento explicitado no art. 210 §2ㅇ. Esse artigo diploma aos índios, o direito de manterem sua identidade cultural, o uso de suas línguas maternas e processos próprios de aprendizagem, cabendo ao Estado proteger e assegurar esses direitos. A escola indígena se constitui em um instrumento de valorização das línguas, dos saberes e das tradições, deixando de ser ferramenta de imposição dos valores culturais da sociedade envolvente. Desempenha, agora, um importante papel no processo de autodeterminação desses povos.

Com a Constituição Federal de 1988 e a nova Lei de Diretrizes e Bases da Educação Nacional (LDB) no. 9.394/96, publicada em dezembro de 1996, completa-se a legislação educacional emanada da Constituição de 1988. Título VIII - Das Disposições Gerais, os Artigos 78 e 79, da nova LDB tratam exclusivamente da educação escolar indígena, garantindo a esses povos o direito de estabelecerem formas particulares de organização de suas escolas, onde a construção 
e a implementação de propostas curriculares relevantes e culturalmente sensíveis, possam promover junto aos alunos indígenas, o exercício pleno da cidadania e da interculturalidade, bem como o respeito as suas particularidades linguístico-culturais.

Segundo o Referencial Curricular Nacional para as Escolas Indígenas (RCNEI, 2005, p. 26), a relação entre o Estado brasileiro e os povos indígenas se reporta como de dominação, "por meio da integração e da homogeneização cultural" que, apesar de ser promulgada a nova Constituição do Brasil, em 1988, onde contemplam em seu Capítulo VIII, (Art. 231 e 232), os direitos indígenas, a sociedade ainda mantém uma postura de domínio e de discriminação para com essa gente.

O sistema educativo reforça o processo de integração das "minorias étnicas, por meio da identificação destas com a sociedade nacional em sua totalidade. Tenta criar um (co) sentimento ideológico" (ACUNZO, 1998, p.15), relacionando-o a temas, a exemplo do progresso e desenvolvimento, não vinculado às realidades locais, de cada grupo étnico, (co) sentimento ideológico este, que cria, em um sentido comum da sociedade nacional, a ideia de que o índio, como pessoa, é indolente, selvagem e sem cultura, pensamento que ainda hoje se perpetuam dentro da sociedade envolvente.

A forma tradicional de transmissão dos saberes entre os indígenas, de maneira geral, obedece a "uma concepção de educação ampla, onde os jovens e as crianças, através da observação e da imitação, aprendem com seus pais, familiares e outros membros da sociedade" (FIORETTI, 2001, p. 32). Assim, os hábitos, os valores, as normas, os costumes e a linguagem estabelecem a identidade dessas comunidades, com estruturas sociais diferentes da sociedade nacional. A educação escolar inserida nessas comunidades acaba criando novas concepções no processo ensino-aprendizagem, trazendo mudanças na concepção do procedimento na transmissão de conhecimento.

A condução da educação indígena, que foi motivo de discussão em vários momentos, e a LDB que a respalda, serviu de base para a elaboração do RCNEI - 1998 (1 a ed.), o qual estabelece as características das escolas indígenas: estas devem ser comunitárias, interculturais, bilíngue, multilíngues, específicas e diferenciadas.

O Art. 78 determina que a União e demais agências federais de fomento à cultura e de assistência aos índios, desenvolvam programas integrados de ensino e pesquisa, de modo a oferecer uma educação bilíngue e intercultural aos indígenas, com vista aos seguintes objetivos: 1. Proporcionar aos índios, suas comunidades e povos, a recuperação de suas memórias históricas, a reafirmação de suas identidades étnicas e a valorização de suas línguas e ciências; 2. Garantir aos índios, suas comunidades e povos, o acesso às informações, conhecimentos técnicos e científicos da sociedade nacional e demais sociedades indígenas e não-índias. 
O art. 79 estabelece que as responsabilidades originárias da União devam estar compartilhadas com os demais sistemas de ensino, determinando procedimentos para o provimento da Educação Escolar Indígena, onde os programas deverão ser planejados com anuência das Comunidades Indígenas. Define ainda esse Artigo, que os programas terão como objetivos:

1. Fortalecer as práticas socioculturais e a língua materna de cada comunidade indígena;

2. Manter programas de formação de pessoal especializado, destinado à educação escolar nas comunidades indígenas;

3. Desenvolver currículos e programas específicos, neles incluindo os conteúdos culturais correspondentes às respectivas comunidades;

4. Elaborar e publicar sistematicamente material didático específico e diferenciado.

Conforme o exposto salienta-se que, se aplicados na íntegra esses artigos da LDB, poderão contribuir para a preservação da cultura dos diversos povos indígenas e ainda para fortalecer a construção de seus currículos, com formas particulares de organização escolar - como, por exemplo, um calendário próprio, que configure a garantia de suas autonomias (Escola e Comunidade), no que se refere à criação, ao desenvolvimento e à avaliação dos conteúdos a serem incorporados em suas aulas.

Verifica-se nessa LDB, uma tentativa de acertos, quando direciona o ensino da Arte às diversidades culturais, regionais e locais, porém continua mergulhada no retrocesso de estabelecê-la a partir da obrigatoriedade, pela legalidade do bloco de conhecimento, sem garantir a sua efetiva realização, já que cairá no processo facultativo de sua execução, além de funcionar como complemento de carga horária de outras disciplinas do currículo escolar.

Para a elaboração do currículo, a LDB enfatiza, no Artigo 26, a importância de levarem-se em conta as características regionais e locais da sociedade, da cultura, da economia e da clientela de cada escola, para que sejam alcançados os objetivos do ensino fundamental. E, no caso das escolas indígenas, o gestor pontuou: Professora, para que seja garantida uma educação diferenciada, não é suficiente que os conteúdos sejam ministrados por meio da língua materna, é preciso inserir conteúdos curriculares próprios, em que a comunidade tenha participação efetiva, contribuindo para o resgate da cultura, quer nas artes, nas histórias de vidas, nos valores, costumes etc.

O currículo deve estar sintonizado com as mudanças da sociedade, mas não abandonando os costumes e a cultura, observação feita pela professora Claudiane A. Ferreira, pertencente à etnia Pankararé, BA, retirado do RCNEI (2005, p. 36). Esse documento foi escrito com o objetivo de contribuir na construção e implementação de propostas curriculares, política e culturalmente adequadas às realidades de cada povo e região, tratando o mesmo de fundamentos gerais de ensino e aprendizagem para o Ensino Fundamental, estruturado em duas partes, a saber: 
Primeira parte: Para Começo de Conversa - esta parte do documento comporta os fundamentos políticos, históricos e antropológicos de uma proposta de educação escolar indígena, entendida como ideal para os índios. Esta primeira parte está voltada para os técnicos das Secretarias estaduais e municipais de ensino e demais órgãos afins. Apresenta ainda o denominador comum, o marco geral presente nas várias situações escolares indígenas, onde reconhece e incentiva a construção de programas curriculares distintos, feitos a partir de projetos históricos e étnicos específicos.

Segunda parte: Ajudando a Construir os Currículos das Escolas Indígenas - Tem a pretensão de fornecer referências para a prática pedagógica dos professores (índios e não-índios). Esta parte do documento está voltada para as salas de aula dos cursos de formação de professores indígenas e para as próprias escolas onde esses professores trabalham.

Este documento é a base para que cada escola indígena construa o seu próprio referencial de análise e avaliação do que nela está sendo feito e, assim, elabore um planejamento adequado, de acordo com o que ela quer realizar. O Referencial é de caráter formativo e não normativo e sua pretensão é fazer refletir sobre o desenvolvimento curricular e as experiências pedagógicas existentes ou que poderão surgir no interior das escolas indígenas. Como bem enfatiza o gestor: o Referencial não é documento pronto para ser utilizado aleatoriamente em qualquer contexto, mas sim ajuda nas atividades do dia a dia.

3.3 Arte Indígena: uma abordagem antropológica

O contingente populacional indígena pertencente a vários grupos étnicos do Estado de Roraima é bastante significativo. Estima-se que, aproximadamente, 44.818 índios fazem parte desse contingente, o que favorece estudos ligados à Antropologia, Linguística, Educação e outras áreas de interesses, haja vista as diversidades culturais existentes.

Em geral, os indígenas não são atingidos pelos censos realizados pelo Instituto Brasileiro de Geografia e Estatística (IBGE), junto à população nacional, isto foi observado quando da realização desta pesquisa (2016/2019), cabendo, portanto, aos Postos Indígenas da FUNAI-RRBrasil, o censo nas aldeias, também denominadas malocas, (termo esse que será adotado neste trabalho). Com 11 (onze) etnias, o Estado de Roraima, computa, segundo a FUNAI (2019), 60.674 índios.

Ocorre que a Fundação Nacional da Saúde (FUNASA) informa um quantitativo estimado em 53.794 índios, embora, nesse levantamento realizado pelo Serviço de Assistência ao Indígena (SAI) do Distrito Sanitário Leste (DSL/FUNASA/RR-2019), fica de fora os indígenas cobertos pelo Distrito Sanitário Yanomami, cujos municípios são Alto Alegre, Caracaraí, Iracema, Mucajaí e Amajarí, estimados em 17.080 índios, só aparecendo indígenas do Distrito Leste. E para a 
Secretaria Estadual do Índio (SEI): 2019 estima-se em 46.897 índios, visto que os ligados ao Conselho Indígena de Roraima (CIR), não aparecem na informação.

As sociedades indígenas são diferenciadas entre si: línguas distintas, traços de caráter e mitos, formas de produzir suas artes. Essas diferenças não podem ser explicadas apenas em decorrência de fatores ecológicos ou razões econômicas. Todavia, mesmo possuindo línguas distintas e diferenças acima citadas, realizam as mesmas festas, cerimônias e vivem sob um mesmo aspecto de vida, utilizam as mesmas matérias primas, quando da produção de sua arte, podendo ser destinadas ao uso cotidiano, festivo ou ritualístico.

Não são discriminadas, porém, as formas de manipular os pigmentos, as plumas, as fibras, os vegetais, a argila, a madeira, a pedra e outros materiais que conferem singularidades, muito embora essas expressões artísticas transcendam as peças como: cuias, cestos, redes, flechas, máscaras, esculturas, cocares, colares, pulseiras etc. Em todos esses casos a ordem estética está vinculada a outros domínios do pensamento, constituindo-se em meio de comunicação entre homem, povos e mundos.

De acordo com Ribeiro (1989), a arte indígena se apresenta como de caráter utilitário e técnico, ficando seu valor artístico relegado a segundo plano. Assim, uma mulher índia ao confeccionar um pote de barro para colocar água (útil), a primeira preocupação é escolher boa argila e deixar a peça cozer no ponto certo (técnico). Aqui, se observa o usual e o técnico, uma vez que o pote pode conter detalhes artísticos ou não. Isso acontece, porque nas sociedades indígenas a arte e a vida se confundem razão por que, um artefato indígena possuirá antes um conteúdo utilitário a uma mensagem artística.

Para os índios da Comunidade da maloca do Canauanim, em tempos passados, essa classificação não era diferente, pois os instrumentos de caça e pesca, os utensílios de cerâmica e de trançados, foi sempre para eles uma questão de sobrevivência e uma maneira de tornar a vida doméstica mais simplificada. Atualmente, esses utensílios são confeccionados na Escola e funcionam como produtos de mercado, uma vez que disputam o comércio urbano e, na própria maloca, a sua comercialização, o que incentiva o aprimoramento das peças, tanto na variedade de estilo como nos modelos, cujo valor varia de acordo com o setor a que se destina.

Na visão de Canclini (1983), quando o capitalismo dependente em seu processo de desenvolvimento se apropria das culturas indígenas, reestrutura o seu significado e função, objetivando agradar o outro, e assim com vista em alternativas de melhoramento de vida, em busca de autonomia econômica, social e política faz com que os índios produzam cada vez mais suas festas e artesanato. Essas alternativas surgem também através da implantação de programas de Governos (Federal, Estadual e Municipal), onde os projetos são desenvolvidos em parcerias com as comunidades indígenas, visando um desenvolvimento sustentável. 
A arte, em todas as culturas, está relacionada efetivamente com algum tipo de aprendizagem, que envolve a expressão verbal, a observação, o ver fazer e a ação de fazer. À medida que o patrimônio cultural é transmitido, colabora com as condições de existência do grupo, seja técnico, estético e/ou outros, variando de uma cultura para outra, em sociedades distintas, podendo ser repassada pelos pais, irmãos mais velhos, especialistas ou pelos anciãos.

De certa forma, a idade de quem detém e para quem é transmitido o conhecimento na sociedade indígena é de suma importância, pois para quem transmitem de forma sistemática os principais elementos da vida de um povo, são considerados os primeiros mestres. A idade da pessoa determina o início do aprendizado das várias e diferentes expressões artísticas, culturais, sociais e religiosas. Outro fator determinante é o sexo, pois muitas vezes a função das mulheres, quando das manifestações culturais, é de espectadora.

Com o decorrer dos anos, as formas de expressão e de comunicação através da arte, bem como sua função e significado, foram redefinidas e, até mesmo, modificadas, para atender às transformações impostas pelo modo de viver, pela cultura, onde os valores dos diferentes povos foram também afetados. Porém, cada período da história da humanidade fora marcado por algum tipo de arte.

Nas sociedades indígenas, a arte está presente nas diversas esferas da vida: nos rituais, na produção de alimentos, nos locais de moradia, nas práticas guerreiras, além de denotar aspectos da organização social do grupo, onde as produções artísticas se constroem a partir de valores, regras, estilos, conhecimentos técnicos, materiais e concepções estéticas distintas entre povos. Essas produções artísticas compõem o meio de comunicação no aspecto da cultura, da vida social e da visão de mundo, por meio dos objetos, das danças, da pintura corporal e dos cantos e são transmitidas e/ou registradas as lembranças, os acontecimentos dos mitos, as relações de parentescos, a existência e os aspectos dos seres sobrenaturais.

Quando das cerimônias comemorativas e rituais de passagem, as atividades cotidianas e toda a comunidade indígena, empenha-se na recriação mítica que envolve o evento. Assim, a arte se veste de maneira refinada, porém atendendo a aspectos simbólicos, expressando, através da dança, da música, do canto, da produção de máscara, da pintura do corpo, nos adornos corporais, nos instrumentos musicais e na gastronomia entre outros, seus costumes e valores mais preciosos, visto que a arte é um dos elementos importantes na formação da identidade do grupo. Identidade esta, definida pela consciência de pertencer a um grupo étnico cultural, marcado pela sua diversidade ao longo do caminhar histórico, com estilo de vida, valores fundamentados em crenças e esperanças no futuro.

A arte, como área de estudo, até poucos anos atrás, era praticamente desconhecida nas escolas indígenas. Sendo esta ligada à vida de todos os povos, em especial, aos índios, para os quais a 
dança, o artesanato, a pintura corporal, constituem-se meios de expressão e comunicação. Hoje, a arte serve, além de complementar atividade curricular, ilustrando através do desenho, da música e do teatro conteúdos, para fixação do conhecimento e é ensinada também como valorização da cultura, por meio do artesanato, ensinado nas salas de aula com uma nova roupagem, de modo a atender à indústria do turismo, ou seja, sua comercialização dependendo do aprimoramento (acabamento) das peças.

\section{CONSIDERAÇÕES FINAIS}

O ensino da Arte ministrado para os alunos do 6 ao 9ㅇ ano do Ensino Fundamental e Médio da Escola Estadual Indígena "Tuxaua Luis Cadete", está voltado, especificamente, para acolher a diversidade do repertório cultural, que o aluno traz de sua casa para a escola; trabalha com os produtos da Comunidade, utilizando os recursos naturais, para confeccionar objetos (artesanatos) tradicionalmente conhecidos no mundo indígena, com função e significados redefinidos tanto para quem os produz como para quem os adquire.

Neste trabalho verificou-se que o professor de Arte e Língua Materna Wapixana, diferente dos demais, não possui a qualificação profissional para o exercício da área, mas possui formação acadêmica em nível de Graduação - Licenciatura detém conhecimentos em técnicas manuais, isto é, domínio do desenho, da pintura e do trançado, bem como da língua Materna Wapixana, com o que soma a carga horária de Arte, em cumprimento ao estabelecido no contrato de trabalho.

O estudo realizado mostrou que a Escola, através do ensino de Arte contribui para o resgate da dança Parixara, buscando junto à Comunidade Indígena, parceria e colaboração.

Evidenciou-se que há uma bibliografia escassa com informações superficiais traçadas em trabalhos datados em 1924 e em 1947.

Verificou-se que o resgate e revitalização da dança Parixara acontece dentro e fora da sala de aula com a parceria da comunidade indígena, principalmente os mais idosos.

Quanto ao problema da pesquisa, como o ensino da Arte do 6ㅇ ao 9o ano do Ensino Fundamental e Ensino Médio da Escola Estadual Indígena "Tuxaua Luis Cadete", colabora para o resgate da dança indígena Parixara? O estudo realizado mostrou que a Escola, através do ensino de Arte, contribui para o resgate da dança Parixara, buscando junto à Comunidade Indígena, parceria e colaboração.

Com relação ao primeiro objetivo: levantar o estado da arte através de literatura pertinente, analisando o ensino de Arte vivenciado pelos alunos do 6 ㅇ ao 9 ㅇ ano do ensino fundamental e médio da referida escola, com a finalidade de verificar sua contribuição para o resgate da dança indígena Parixara, evidenciou-se que há uma bibliografia escassa, com informações superficiais, traçadas em trabalhos datados em 1924 e 1947, de autoria de Theodor Koch-Grünberg e de 
Lucila Herrmann, respectivamente, ambos consideram a dança Parixara de cunho ritualístico ligada à vida econômica do grupo étnico. As informações colhidas nas leituras foram primordiais para entender-se a historicidade da dança, sua função e significado; observou-se também que, através dela (dança), casamento (ajuntamento) era realizado, isto quando recebiam outras malocas para algum festejo. Dançavam Parixara os guerreiros, homens fortes da maloca, quando saíam à caçada ou para pescaria em sinal de boa sorte, bem como quando da volta desses mesmos guerreiros, em sinal de agradecimento pelo sucesso alcançado, com o saldo da caçada. Outra informação para comemorar o ano novo, boa saúde, fertilidade dos animais e harmonia entre as tribos indígenas, os índios Wapixana (povo originário desta região e grupo de origem da dança), dançavam a Parixara por longos dias, até o término da comida Damorida e das bebidas Pajuarú e Caxiri.

Teoricamente, o ensino da Arte ministrado na escola, é de forma superficial, uma vez que a preocupação da escola reside em os alunos conhecerem a arte tradicional, através da dança e aprender como utilizar os recursos da natureza para confeccionar o artesanato.

Com relação ao objetivo: identificar no contexto escolar e Comunidade Indígena, o processo de resgate e revitalização da dança Parixara, através de observação de natureza artificial em sala de aula, relatos de histórias de vida e de entrevistas intensivas em especial os mais idosos, visando consubstanciar a pesquisa de campo, verificou-se que, para resgatar e revitalizar a dança Indígena Parixara, a união da Escola e da Comunidade Indígena foi de suma importância. Nas salas de aula observou-se a transmissão do conhecimento tradicional, por meio das histórias contadas pelos membros da Comunidade Indígena sobre a dança Parixara. Naquele momento foi observado que os alunos do 60 ao 9o ano, queriam saber mais sobre o assunto e assim resolveram colocar em prática a dança: criaram um grupo cultural denominado "Kana'u Wau San Nau" que, na língua Wapixana significa "Filhos de Canauanim", formado por 20 (vinte) alunos do ensino Fundamental, 10 (dez) alunos do ensino Médio e 16 membros da Comunidade Indígena.

\section{REFERÊNCIAS}

ACUNZO, Mario. La educación escolar entre los Mixe (primeros intentos). Revista Pueblos indígenas y educación. Ediciones ABYA-YALA. Proyecto educación bilíngüe intercultural. Quito, Equador, 1998.

ANDRÉ, M. Etnografia da prática escolar. Campinas: Papirus, 1998.

BARBOSA, Ana Mae. Arte- educação (livro eletrônico): leitura no subsolo, Ana Mae Barbosa (Org.) - 1a edição - São Paulo: Cortez, 2018. 
BRANDÃO, Carlos da Fonseca. LDB Passo a Passo. São Paulo: Atual/ Avecampo, 2007.

BRASIL. Constituição da República Federativa do Brasil. Brasília: Congresso Nacional, 1988. - Ministério da Educação e Cultura. Lei de Diretrizes e Bases da Educação Nacional - LDB Lei 9.394. Brasília, DF: MEC, 1996.

Decreto $n^{\circ}$ 5.051. Convenção $n^{\circ} 169$ da OIT sobre povos indígenas e tribais: MEC/SEF, 2002.

- Diretrizes Curriculares Nacionais para Educação Indígena. Brasília: Ministério da Educação, 2013.

FERNANDES, M. L; GUIMARÃES, M. L. S. História, diversidade, política, educação, gênero e etnia em Roraima. Boa Vista/Roraima: UFRR, 2010.

- Ministério da Educação e Cultura. Secretaria de Educação Fundamental. Referencial Curricular Nacional para a Educação Infantil. Brasília: MEC/SEF, 2005.

BUORO, Anamélia Bueno. O olhar em construção: uma experiência de ensino e aprendizagem da arte na escola. São Paulo: Cortez, 2000.

CANCLINI, Nestor Garcia. As Culturas populares do capitalismo. São Paulo: Brasiliense, 1983.

DECROLY, Ovídio. Os grandes pensadores. Revista Nova Escola. Edição Especial. São Paulo: Abril, 1996.

DELORS, Jacques. Educação: um tesouro a descobrir. São Paulo: Cortez; Brasília, DF: MEC: UNESCO, 2006.

FARAGE, Nádia. As Muralhas dos Sertões: os povos indígenas no Rio Branco e a colonização. Rio de Janeiro: Paz e terra, ANPOCS, 1991.

FERNÁNDES GONZÁLES, Leopoldo Jesús, Cadernos de Antropologia da Educação n 1 Antropologia e Educação. Petrópolis, RJ: Vozes, 2005.

Caderno de Antropologia da Educação no 4 - O método na Antropologia da Educação. Petrópolis, RJ: Vozes, 2005.

- Cadernos de Antropologia da Educação n. 5 - Linguagem, Sociedade, Cultura e Educação. Petrópolis, RJ: Vozes, 2005.

FERREIRA, M. L. A educação escola indígena: um diagnóstico crítico da situação do Brasil In: SILVA, Aracy Lopes; FERREIRA, Mariana Kawal Leal (Orgs.). Antropologia, História e Educação: a questão indígena e a Escola. São Paulo: Global, 2001.

FIORETTI, Elena Campo. Propuesta de Recomendaciones Fundamentadas em la Educación Multi e Intercultural para la Formación de Professores de la Escoelas Estatales de Boa Vista, Roraima. Tesis para obtención del grado de Máster en Ciências de la Educación Superior por la Universidad de Matanzas Camilo Cienfuegos, Cuba, 2001.

FREITAS, M.T.A. Psicología e educação: um intertexto Vygotski e Bakhtin. São Paulo: Ática, 1994. 
FUNDAÇÃO Nacional do Índio (FUNAI). Relatório Populacional Indígena. Boa Vista, RR: Ministério da Justiça - Administração Executiva Regional de Boa Vista, 2006 / 2007.

FUSARI, Maria Felisminda de Resende; FERRAZ, Maria Heloísa de Toledo: Arte na Educação Escolar. São Paulo: Cortez, 2001.

GENZUK, M. A Synthesis of Ethnographic Research. Occasional Papers Series. Center for Multilingual, Multicultural Research (Eds.). Center for Multilingual, Multicultural Research, Rossier School of Education. Los Angeles: University of Southern California, 1993.

GODOY, Arilda S., Introdução à pesquisa qualitativa e suas possibilidades, In: Revista de Administração de Empresas, v.35, n.2, Mar. / Abr. 1995.

HERRMANN, Lucila. A Organização Social dos Vapidiana. Dissertação de Mestrado da Escola livre de Sociologia e Política de São Paulo, 1947.

KOCH-GRÜNBERG, Theodor. Del Roraima al Orenoco. Ediciones Del Banco Central de Venezuela, Tomo III, 1924.

LAKATOS, Eva Maria. Fundamentos de metodologia Científica. São Paulo: Atlas, 2003.

LIMA, José Najib da Silva. Educação Indígena de Roraima: rumo à constituição do núcleo de educação indígena. Monografia de Especialização em Metodologia de Pesquisa Científica. Boa Vista, RR: UFR, 1993.

LIMA, José Airton de Silva. Proyecto Pedagógico de la escuela indígena de Malacacheta: su interacción com la comunidad. Tesis para obtención del grado de Máster em Educación Superior por la Universidad de Matanzas "Camilo Cienfuegos”, Cuba, 1999.

LÜDKE, Menga; ANDRÉ, Marli E. D. A. Pesquisa em educação: abordagens qualitativas. São Paulo: EPU, 1986.

MAIA, D. M. de S. Os Wapixanas da Serra da Moça: entre o uso e desuso das práticas cotidianas (1930/1990). Boa Vista/Roraima: UFRR, 2014.

MARTINS, Alberto; Kok, Glória. Roteiros Visuais no Brasil: artes indígenas. São Paulo: Claro Enígma, 2014.

MATOS, M. B. de. As colturas indígenas e gestão das escolas da Comunidade Guariba/RR: uma etnografia. 2013. 265 fls. Tese (Doutorado em Educação). São Leopoldo/RS: UNISINOS, 2013. MELATTI, Júlio Cezar. Índios do Brasil. São Paulo: HUCITEC, 1994.

MENEZES, S. Retratos - Índios: Resgate cultural. Desafios do Desenvolvimento, Brasília, ano 6, edição 52, julho 2009.

MILHOMEM, M. Santana Ferreira dos Santos. Educação Escolar Indígena: as dificuldades do currículo intercultural e bilíngüe. Universidade Federal de Sergipe. Revista Fórum. Ano2, v. 3. Jan./jun., 2008, p. 95-102.

MORSE, Janice. Qualitative research methods. London: Sage, 1994. 
NASCIMENTO, R. N. Interculturalidade e educação escolar indígena em Roraima: da normatização à prática cotidiana. 2010. 266f. Tese de Doutorado - UFPE, Recife, 2014.

OLIVEIRA FILHO, João Pacheco de. O nosso Governo: Os Ticunas In: Boletim Museu Paraense Emílio Goeldi. Belém. V.3(2), 1988.

OLIVEIRA, Maria Marly de. Como fazer projetos, Monografias, Dissertações e Teses. Rio de Janeiro: Elsevier, 2005.

RIBEIRO, Berta G. (Coord.). Suma Etnológica Brasileira - Arte Índia. V. 3, Petrópolis: RJ. Vozes, 1987.

RORAIMA. Índios e Brancos de Roraima. Coleção Histórico-antropológico, n. 2, Roraima: Centro de Informação Diocese de Roraima (CIDR), 1990.

RIBEIRO, Berta G. Arte Indígena, Linguagem Visual / Indigenous Art, Visual Language. Belo Horizonte: Itatiaia; São Paulo: Univ. de São Paulo, 1989.

SANTILLI, S. Paulo. As Fronteiras da República: história e política entre os Makuxi no vale do rio Branco. Núcleo de História indígena e indigenismo / Fundação de Amparo à Pesquisa do Estado de São Paulo (FAPESP). São Paulo: NHII- USP, 1994.

SILVA, Aracy Lopes da. Índios. São Paulo: Ática, 1988.

SILVA JUNIOR, Tércio Araújo da. Roraima o Brasil do Hemisfério Norte: Diagnóstico Científico e Tecnológico para o Desenvolvimento. Roraima: AMBTEC, 1994.

SILVA, Orlando Sampaio. Sociedade Wapixana: Ritos e Mitos (Registros Preliminares). Revista do Museu Paulista. Nova Série - V. XXX. São Paulo: USP, 1995.

SILVA, A. L; FERREIRA, M (Orgs.). Antropologia, História e Educação: a questão Indígena e a Escola. São Paulo: Global, 2001.

SILVA, Edson; Silva, Maria da Penha da (Orgs.) A temática indígena em Sala de Aula: reflexão para o ensino a partir da Lei 11.645/2008. Recife: Ed. Universitária da UFPE, 2013.

SILVA, Julieta. Festa Parixara. Boletim do Museu Integrado de Roraima. Boa Vista, 3 (1):36-39, julho, de 1995.

SOUSA, J.M. O olhar etnográfico da escola perante a diversidade cultural In: Psi 21 de junho de 2000. Disponível em: http://www2.uel.br/ecb/psicologia/revista/textov2n16.htm. Acesso em: 23 fev 2007.

THIOLLENT, Michel. Metodologia da Pesquisa- ação. São Paulo: Cortez, 2004.

TRIVIÑOS, Augusto Nibaldo Silva. Introdução à Pesquisa em Ciências Sociais: a pesquisa qualitativa em educação. São Paulo: Atlas, 2006.

VARELA, Noemia de A. A Formação do Arte - Educador no Brasil In: Arte - educação: Perspectiva. Recife: SEEP,1988. 
VIDAL, Luz Boelizt. As Pesquisas Mais Freqüentes em Etnologia e História Indígenas na Amazônia: Uma Abordagem Musical In Revista de Antropologia. São Paulo, USP, n. 34, 1991. O Sistema de Objetos nas Sociedades Indígenas: a Arte e Cultura Material. In: SILVA, Aracy Lopes da e GRUPIONI, Luís Donisete B. (orgs.) A Temática indígena na escola: novos subsídios para professores de 1ำ e 2o grau, Brasília: MEC /MARI/UNESCO, 1995 